\title{
Stereocontrolled Acyclic Diene Metathesis Polymerization
}

\author{
Ting-Wei Hsu, ${ }^{1 \dagger}$ Samuel J. Kempel,${ }^{1 \dagger}$ Alyssa P. Felix Thayne, ${ }^{1}$ Quentin Michaudel ${ }^{1,2 *}$ \\ ${ }^{1}$ Department of Chemistry, Texas A\&M University; College Station, Texas 77843, United States. ${ }^{2}$ Department of \\ Materials Science and Engineering, Texas A\&M University; College Station, Texas 77843, United States.
}

*Corresponding author. Email: quentin.michaudel@chem.tamu.edu

$\dagger$ These authors contributed equally to this work

\begin{abstract}
The cis/trans geometry of olefins is known to dramatically influence the thermal and mechanical properties of polyalkenamers. Yet, polymerization methods that allow the practitioner to efficiently control this parameter are scarce. Herein, we report the development of a stereoretentive acyclic diene metathesis (ADMET) polymerization that capitalizes on the unique reactivity of dithiolate $\mathrm{Ru}$ carbenes combined with cis monomers. These Ru catalysts exhibit exquisite retention of the cis geometry and tolerate many polar functional groups, enabling the synthesis of all-cis polyesters, polycarbonates, polyethers, and polysulfites. Additionally, the stereoretentive ADMET is characterized by low catalyst loadings and tolerance toward trans impurities in the monomer batch, which should lend to ready implementation at large-scale. Remarkably, modulation of the reaction conditions including temperature and reaction time leads to an erosion of stereoretention, thereby permitting a stereocontrolled synthesis of polyalkenamers with predictable cis:trans ratios. The impact of the cis:trans alkene content within the polymer backbone on the thermal properties was clearly demonstrated through differential scanning calorimetry and thermogravimetric analysis. Stereocontrolled ADMET provides a unique synthetic approach toward materials with precise structures and tailored properties.
\end{abstract}

Perhaps best exemplified by the numerous modifications of the venerable Wittig and Horner-WadsworthEmmons reactions, controlling the cis or trans $(Z$ or $E$ ) geometry of alkenes in organic molecules has motivated the development of a myriad of synthetic methods to access either isomer selectively ${ }^{1}$. Indeed, the configuration of alkenes dramatically impacts the shape, properties, and reactivity of compounds. Interestingly, despite the importance of this structural parameter on the thermal and mechanical, properties of polymeric materials ${ }^{2}$, few polymerizations allow the practitioner to precisely dictate the cis:trans ratio within macromolecules and these processes are limited to a narrow scope of monomers ${ }^{3-6}$. Among the classic examples illustrating the influence of alkene geometry over material properties, trans-polyisoprene (gutta percha) is a hard, brittle semi-crystalline material, once used in the manufacturing of golf balls ${ }^{7}$, while the more amorphous cis-polyisoprene is an elastic material found in latex gloves 8,9 .

Ring-opening metathesis polymerization (ROMP) and acyclic diene metathesis (ADMET) polymerization are among the most powerful methods to access unsaturated polymers, but typically afford cis/trans mixtures or transrich linkages dictated by the thermodynamic stability of the products ${ }^{10}$. The recent introduction of stereoselective $\mathrm{Mo}, \mathrm{W}$, and $\mathrm{Ru}$ catalysts has paved the way for kinetic control of the olefin metathesis process, overcoming the product preference for trans alkenes ${ }^{11-16}$. While careful catalyst design has afforded impressive cis selectivity in a variety of transformations based on olefin metathesis, only a limited number of polymers have been synthesized through stereoselective processes, all through ROMP. For example, dithiolate Ru carbenes uniquely preserve the configuration of the starting olefin throughout the metathesis process ${ }^{17-19}$. Hoveyda and coworkers demonstrated that ROMP of norbornene or cyclooctadiene with this family of stereoretentive catalysts leads to exquisite cis selectivity along the polymer backbone ${ }^{12}$. Choi and coworkers expanded the scope of norbornene-type monomers for 
a

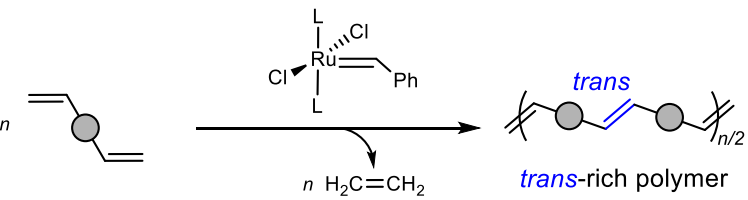

b
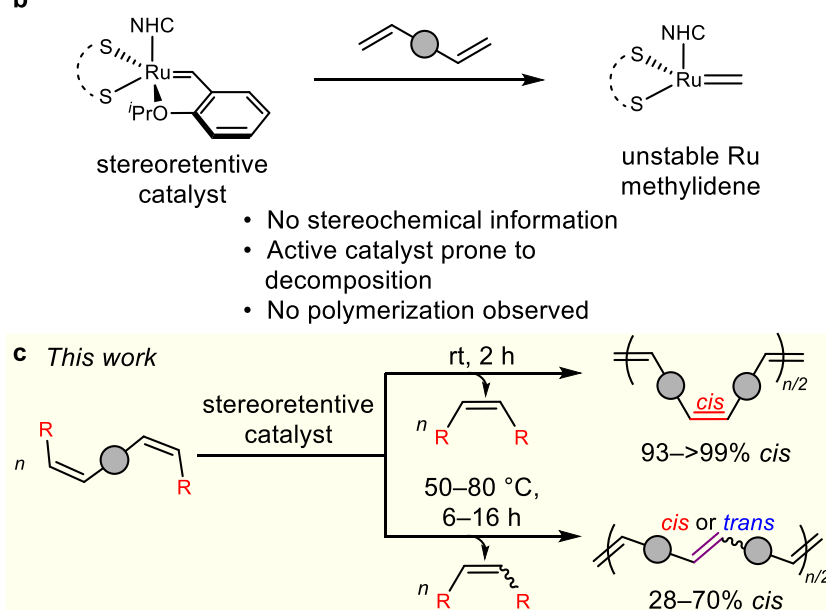

- Broad array of cis-rich polymers

- cis content tunable as a function of temperature

- Modular properties based on cis:trans ratio

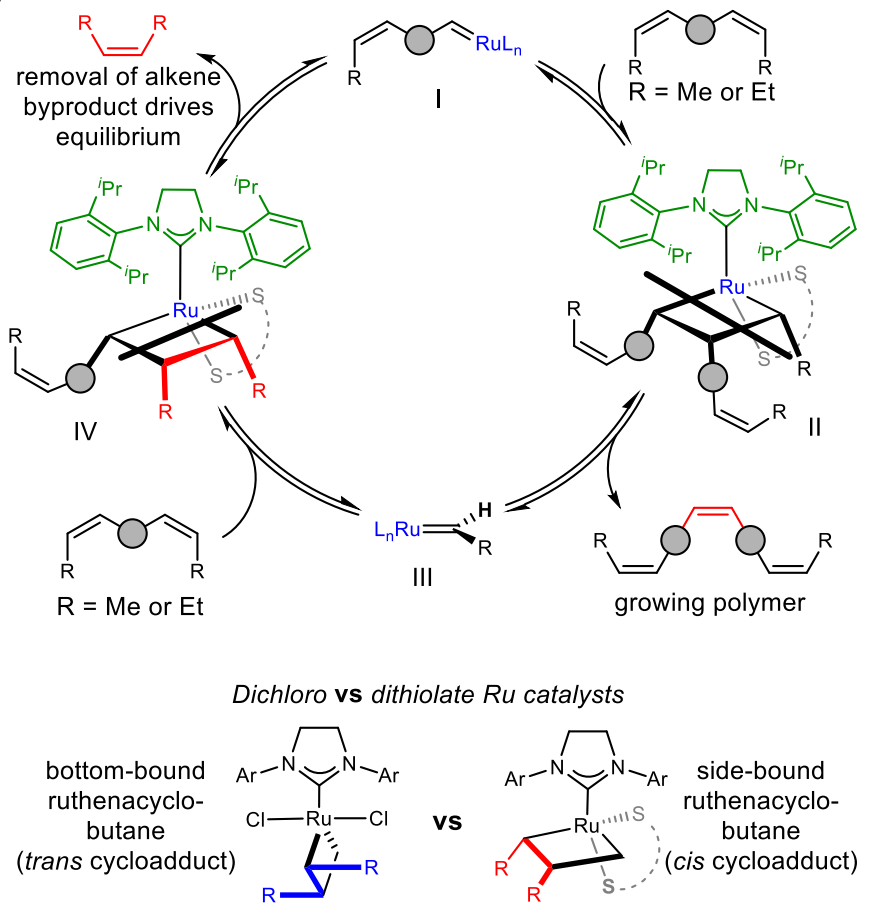

Fig. 1. Design of stereocontrolled ADMET. a. Typical ADMET polymerizations favor high trans alkene content. b. Dithiolate Ru catalysts lead to highly unstable Ru methylidenes with terminal diene monomers. c. Design of a stereocontrolled ADMET modulated by the reaction temperature. d. Proposed stereoretentive ADMET cycle (the initial reaction between the $\mathrm{Ru}$ precatalyst and the monomer was omitted for clarity). e. Bottom-bound olefin approach with dichloro Ru catalysts compared to side-bound approach with dithiolate Ru catalysts.

stereoretentive ROMP ${ }^{15}$, and reported that the shear stability of the resulting all-cis polymers was greatly enhanced relative to that of their all-trans counterparts. Recently, we harnessed the reactivity of this family of catalysts in combination with [2.2]paracyclophane diene monomers to synthesize all-cis poly(p-phenylene vinylene)s (PPVs) with living characteristics and unusually high molar masses ${ }^{20,21}$. While these examples of stereoretentive ROMP afforded extremely precise polymeric structures (narrow molar mass distributions, perfect cis stereoselectivity, etc.), the ROMP process typically requires highly strained monomers thereby narrowing the scope of accessible polymers. Further, these scarce examples only afforded strict cis selectivity. Herein, we report the implementation of stereoretentive olefin metathesis into the ADMET process as a versatile method to access all-cis polyalkenamers. Additionally, careful optimization of the reaction conditions provided unprecedented stereocontrol over the proportion of cis and trans alkenes throughout the polymer backbone. Several families of alkene-containing polymers were synthesized with predictable cis:trans ratios from 20:80 to $>99: 1$, providing a valuable strategy to tune the thermal properties of several types of polymers.

One of the major advantages of ADMET over other polymerizations based on olefin metathesis is the simplicity and ubiquity of the monomer structure characterized by the presence of two terminal alkenes. These $\alpha, \omega-$ dienes are polymerized following a step-growth mechanism, where removal of ethylene gas is the thermodynamic driving force (Fig. 1a) ${ }^{22,23}$. Pioneered by Wagener and coworkers ${ }^{24}$, ADMET polymerization has been employed to synthesize an impressive variety of polymers including polyethylene with precise alkyl branching ${ }^{25}$, ionic polymers ${ }^{26}$, and conjugated polymers, albeit with high trans alkene content ${ }^{27}$. Developing a stereoselective ADMET would therefore open the door to a cornucopia of stereodefined polymers for a variety of applications, but several pitfalls were identified at the outset of this work. Since ADMET polymerization relies on iterative couplings between terminal dienes that are neither cis nor trans (Fig. 1b), typical ADMET monomers preclude the stereoretentive mechanism of dithiolate $\mathrm{Ru}$ catalysts. Additionally, the $\mathrm{Ru}$ methylidene intermediate generated upon reaction of the dithiolate carbene with a terminal alkene is known to readily decompose, likely through a 1,2-shift of the anionic sulfide ligand 14. Hoveyda and coworkers reported an elegant strategy to circumvent the premature deactivation of the catalyst in 
the cross metathesis of terminal alkenes through in situ methylene capping with gaseous cis-but-2-ene ${ }^{28}$. This approach, however, is not compatible with ADMET, which requires constant removal of volatile alkene by-products to drive the step-growth process. We envisioned that synthesizing capped monomers with pre-installed cis geometry would obviate both catalyst decomposition and the need for cis-but-2-ene, as well as allow the desired stereoretention (Fig. 1c). While non-terminal dienes have previously been polymerized using ADMET ${ }^{29}$, the retention of alkene configuration of the monomer was not observed with Grubbs' second generation catalyst. The proposed mechanistic cycle of a stereoretentive ADMET is outlined in Fig. 1d. The [2+2] cycloaddition of carbene intermediate $\mathbf{I}$ with a capped monomer or a growing polymer would afford ruthenacyclobutane II and subsequent cycloreversion would lead to the formation of stabilized $\mathrm{Ru}$ ethylidene $(\mathrm{R}=\mathrm{Me})$ or propylidene $(\mathrm{R}=\mathrm{Et})$ intermediate III. In contrast to the bottom-bound approach typically observed with dichloro $\mathrm{Ru}$ carbenes, the dithiolate ligand is known to enforce a side-bound approach of the monomer with the alkene substituents pointing away from the bulky aryl groups of the NHC ligand (Fig. 1e) ${ }^{18}$. Following cycloreversion, Ru-ethylidene/propylidene III would further react with another capped alkene (from a monomer or a growing oligomer) to form ruthenacycle IV, whose cycloreversion would regenerate a reactive $\mathrm{Ru}$ carbene and expel volatile cis-but-2-ene $(\mathrm{R}=\mathrm{Me})$ or cis-hex-3-ene $(\mathrm{R}=\mathrm{Et})$. Removal of either byproduct would drive all equilibriums toward a productive cycle.

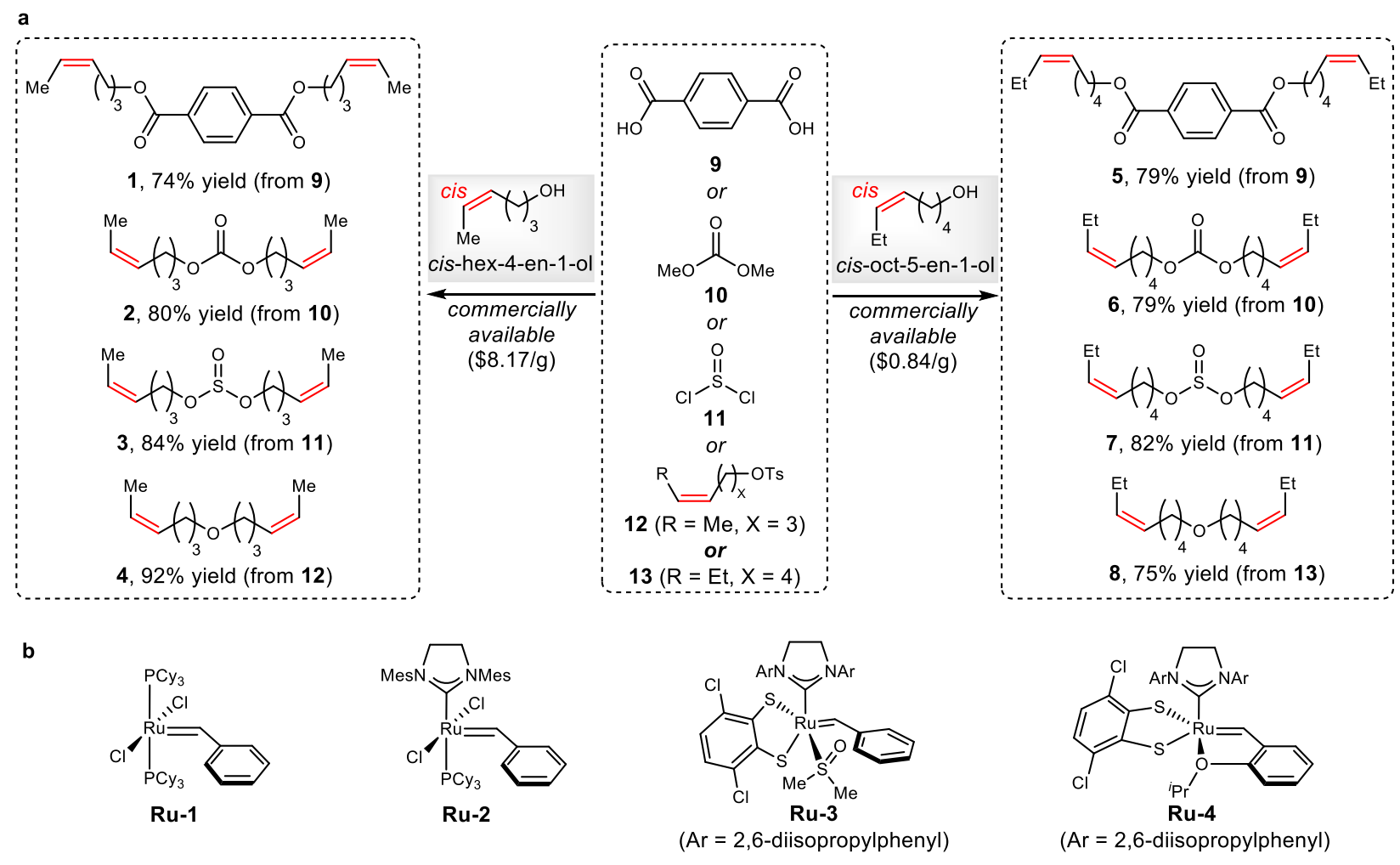

Fig. 2. Monomers and Ru catalysts. a. Readily accessible methyl- and ethyl-capped cis,cis-monomers from commercially available reagents. b. Catalysts screened in stereocontrolled ADMET.

Capitalizing on the inexpensive and readily available cis-hex-4-en-1-ol and cis-oct-5-en-1-ol ${ }^{30}$, a variety of monomers were synthesized in one or two steps in high yields (Fig. 2a and Supplementary Information) ${ }^{31-34}$. These two groups of monomers (1-4 and 5-8) were selected to interrogate the tolerance of dithiolate catalysts to polar monomers containing Lewis basic functional groups, as well as the effect of increasing the size of the capping group (Et vs $\mathrm{Me}$ ) on the polymerization. As a benchmark of cis/trans selectivity, terminal diene $\mathbf{1 4}$ was polymerized under standard ADMET conditions using Ru-1 (Fig. 2b) in 1,2,4-trichlorobenzene at $50{ }^{\circ} \mathrm{C}$ under high vacuum ( 100 mtorr) for $16 \mathrm{~h}$. The resulting polymer, poly-1 $\left(M_{\mathrm{n}}=13.1 \mathrm{~kg} / \mathrm{mol}, D=2.61\right)$, was isolated with $23 \%$ cis content as established by ${ }^{1} \mathrm{H}$ NMR (Table 1, entry 1 and Supplementary Fig. 4). As expected, the polymerization of 14 with dithiolate 
Table 1. Optimization of Stereoretentive ADMET with Dithiolate Ru Catalysts

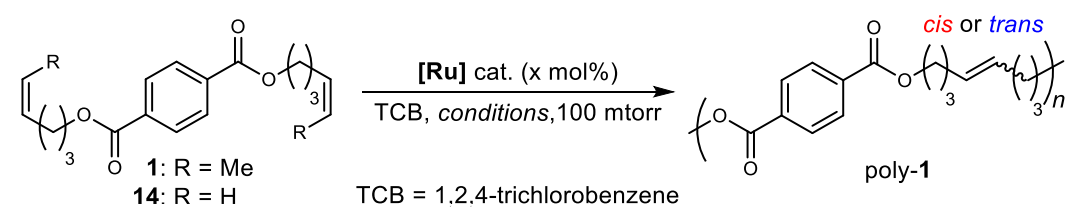

\begin{tabular}{|c|c|c|c|c|c|c|c|c|}
\hline entry & monomer & {$[\mathbf{R u}](\mathrm{mol} \%)$} & $\begin{array}{c}\text { Temperature } \\
\left({ }^{\circ} \mathrm{C}\right)\end{array}$ & $\begin{array}{c}\text { Time } \\
\text { (h) }\end{array}$ & $\begin{array}{c}\text { Conversion } \\
(\%)^{\mathrm{a}}\end{array}$ & $\begin{array}{c}M_{\mathrm{n}} \\
(\mathrm{kg} / \mathrm{mol})^{\mathrm{b}}\end{array}$ & $\theta^{c}$ & $\begin{array}{l}\text { cis } \\
(\%)^{d}\end{array}$ \\
\hline 1 & 14 & Ru-1 (5) & 50 & 16 & 100 & 13.1 & 2.61 & 23 \\
\hline 2 & 14 & Ru-3 (5) & 50 & 16 & - & - & - & - \\
\hline 3 & 14 & Ru-4 (5) & 50 & 16 & - & - & - & - \\
\hline 4 & 1 & Ru-1 (5) & 50 & 16 & 100 & 4.3 & 1.50 & 29 \\
\hline 5 & 1 & Ru-1 (5) & 80 & 16 & 100 & 11.8 & 2.76 & 26 \\
\hline 6 & 1 & Ru-2 (5) & 50 & 16 & 100 & 13.4 & 2.00 & 21 \\
\hline 7 & 1 & Ru-3 (5) & 50 & 16 & 100 & 13.1 & 2.13 & 54 \\
\hline 8 & 1 & Ru-3 (5) & 50 & 4 & 100 & 12.6 & 1.74 & 62 \\
\hline 9 & 1 & Ru-3 (5) & 50 & 2 & 100 & 11.8 & 1.81 & 73 \\
\hline 10 & 1 & Ru-3 (0.5) & 23 & 2 & 100 & 13.5 & 1.88 & $>99$ \\
\hline 11 & 1 & Ru-4 (0.5) & 23 & 2 & 100 & 13.0 & 1.75 & $>99$ \\
\hline 12 & 1 (95\% cis) & Ru-3 (0.5) & 23 & 2 & 100 & 7.7 & 1.63 & $>99$ \\
\hline
\end{tabular}

${ }^{\mathrm{a}}$ Conversion of monomer determined by ${ }^{1} \mathrm{H}$ NMR analysis of the crude mixture. ${ }^{\mathrm{b}} M_{\mathrm{n}}$ determined through size exclusion chromatography (SEC) in THF against polystyrene standards (RI detection). ${ }^{\mathrm{c}} M_{\mathrm{w}} / M_{\mathrm{n}} .{ }^{\mathrm{d}}$ Calculated using ${ }^{1} \mathrm{H}$ NMR analysis.

catalysts Ru-3 and Ru-4 (Fig. 2b) did not afford any polymers (Table 1, entries 2 and 3). Switching to methyl-capped monomer $\mathbf{1}$ did not result in any increase of cis content with Ru-1 (Table 1, entries 4 and 5) nor with Ru-2 (Table 1, entry 6). Of note, increasing the temperature with Ru-1 allowed the production of poly-1 with higher molar masses, but did not significantly affect the cis content. By contrast, methyl-capped monomer $\mathbf{1}$ in combination with Ru-3 afforded poly-1 with 54\% cis content (Table 1, entry 7). Interestingly, when the reaction time was decreased to $4 \mathrm{~h}$ or $2 \mathrm{~h}$, the molar masses of poly-1 did not significantly decrease $\left(M_{\mathrm{n}}=12.6 \mathrm{~kg} / \mathrm{mol}\right.$ and $11.8 \mathrm{~kg} / \mathrm{mol}$, respectively), but the cis selectivity improved to $62 \%$ and $73 \%$ (Table 1, entries 8 and 9). To our delight, running the polymerization at room temperature to further increase kinetic control over the polymerization and at lower catalyst loading $(0.5 \mathrm{~mol} \%)$ afforded perfect cis selectivity $\left(M_{\mathrm{n}}=13.5 \mathrm{~kg} / \mathrm{mol}, Ð=1.88\right.$, Table 1, entry 10). The low catalyst loading permitted by the high reactivity of $\mathbf{R u - 3}$ is promising for large-scale applications. Notably, Ru-4 furnished an all-cis polymer of similar size $\left(M_{\mathrm{n}}=13.0 \mathrm{~kg} / \mathrm{mol}, Ð=1.75\right)$ when subjected to the same conditions (Table 1, entry 11). Finally, the tolerance to trans impurities in the monomer batch was probed. Indeed, trans alkenes are known to react slower with stereoretentive dithiolate catalysts than the cis congeners due to the steric clash between one substituent of the ruthenacycle and the NHC ligand, ${ }^{19}$ which would potentially allow the use of less expensive, stereochemically impure 


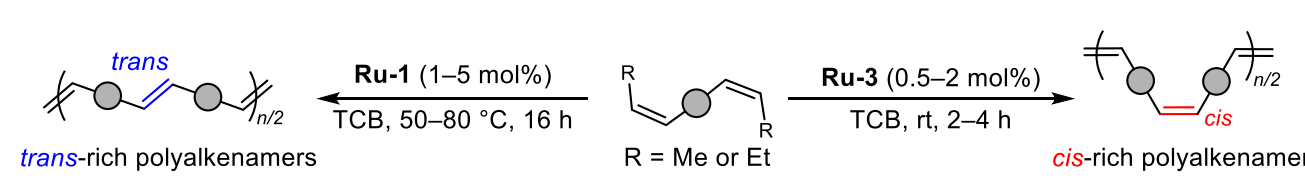

trans-rich polyalkenamers

cis-rich polyalkenamers<smiles>CCOC(=O)c1ccc(C(=O)OCC(C)C)cc1</smiles>

Ru-1: $26 \%$ cis,

$M_{\mathrm{n}}=11.8 \mathrm{~kg} / \mathrm{mol}, \oplus=2.76$

Ru-3: $99 \%$ cis,

$M_{\mathrm{n}}=13.5 \mathrm{~kg} / \mathrm{mol}, \oplus=1.88$

b From ethyl-capped monomers<smiles>CC(C=CC(C)(C)C)CC(C)C(=O)c1ccc(C(=O)OC(C)(C)C)cc1</smiles>

Ru-1: $22 \%$ cis,

$M_{\mathrm{n}}=7.8 \mathrm{~kg} / \mathrm{mol}, \oplus=1.97$

Ru-3: $94 \%$ cis,

$M_{\mathrm{n}}=15.9 \mathrm{~kg} / \mathrm{mol}, \emptyset=1.87$

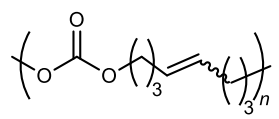

poly-2

Ru-1: $24 \%$ cis

$M_{\mathrm{n}}=10.0 \mathrm{~kg} / \mathrm{mol}, \emptyset=1.55$

Ru-3: $99 \%$ cis,

$M_{\mathrm{n}}=8.2 \mathrm{~kg} / \mathrm{mol}, \emptyset=1.50$

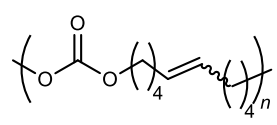

poly-6

Ru-1: $16 \%$ cis,

$M_{\mathrm{n}}=7.5 \mathrm{~kg} / \mathrm{mol}, \ominus=1.46$

Ru-3: $99 \%$ cis

$M_{\mathrm{n}}=7.2 \mathrm{~kg} / \mathrm{mol}, \oplus=1.40$

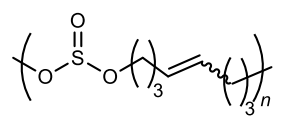

poly-3

Ru-1: $16 \%$ cis,

$M_{\mathrm{n}}=10.1 \mathrm{~kg} / \mathrm{mol}, \oplus=1.41$

Ru-3: $99 \%$ cis,

$M_{\mathrm{n}}=12.0 \mathrm{~kg} / \mathrm{mol}, \oplus=1.67$

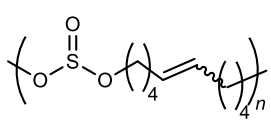

poly-7

Ru-1: $12 \%$ cis,

$M_{\mathrm{n}}=6.8 \mathrm{~kg} / \mathrm{mol}, \oplus=1.33$

Ru-3: $99 \%$ cis,

$M_{\mathrm{n}}=10.1 \mathrm{~kg} / \mathrm{mol}, \emptyset=1.43$ $x_{0}+x_{3}\left(t_{3}\right)$

poly-4

Ru-1: $19 \%$ cis,

$M_{\mathrm{n}}=8.2 \mathrm{~kg} / \mathrm{mol}, \emptyset=1.42$

Ru-3: $99 \%$ cis,

$M_{\mathrm{n}}=9.2 \mathrm{~kg} / \mathrm{mol}, \oplus=1.31$

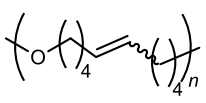

poly-8

Ru-1: $20 \%$ cis,

$M_{\mathrm{n}}=5.7 \mathrm{~kg} / \mathrm{mol}, \emptyset=1.25$

Ru-3: $93 \%$ cis,

$M_{\mathrm{n}}=14.0 \mathrm{~kg} / \mathrm{mol}, \emptyset=1.62$

Fig. 3. Polymer scope of stereocontrolled ADMET. a. Polymers from methyl-capped monomers (poly-1-poly-4). b. Polymers from ethyl-capped monomers (poly-5-poly-8).

monomers. Impressively, polymerization of $95 \%$ cis 1 led to poly-1 with $>99 \%$ cis content and a slightly diminished molar mass $\left(M_{\mathrm{n}}=7.7 \mathrm{~kg} / \mathrm{mol}, Ð=1.63\right.$, Table 1, entry 12). This finding should open the door to the synthesis of a variety of monomers through diverse synthetic routes (e.g., hydrogenation of alkynes with Lindlar's catalyst, Wittig olefination, etc.) without the need for perfect diastereoselectivities.

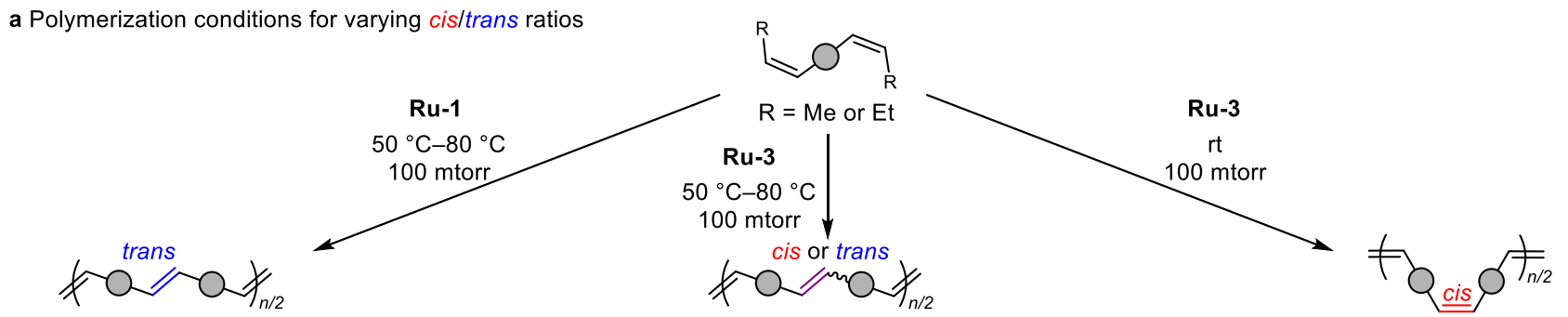

b Hydrolysis study of poly-1

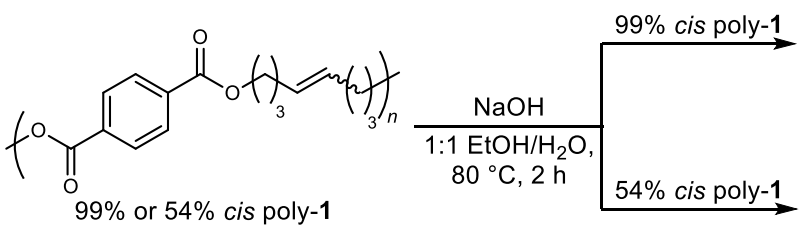

$99 \%$ or $54 \%$ cis poly- 1

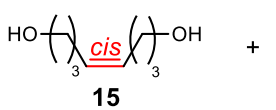

15

only cis diol recovered

cis or trans

$\mathrm{Hot}_{15}$ mafy ${ }_{3} \mathrm{OH}+$

cis and trans diol recovered

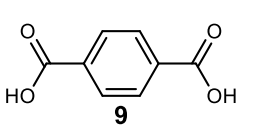

no olefin migration observed

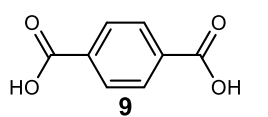

no olefin migration observed

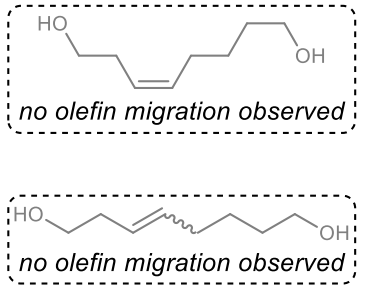

Fig. 4. Selectivity in stereocontrolled ADMET. a. Preparation of polyalkenamers with different cis/trans content via ADMET using different reaction conditions. b. Hydrolysis of poly-1 ( $99 \%$ cis from Table 1, entry 10 and 54\% cis from Table 1, entry 7) indicates that olefin migration does not take place with Ru-3. 
Under optimized conditions, all-cis poly-2, poly-3, and poly-4 were also obtained from monomers 2, 3, and 4, respectively, displaying the excellent functional group tolerance of stereoretentive ADMET (Fig. 3a). These ADMET conditions are also milder compared to traditional ADMET processes that are generally conducted at higher temperatures for several hours or even days. After determining suitable conditions for the polymerization of methylcapped monomers, the ethyl-capped monomers were found to only require moderate increases in reaction time $(4 \mathrm{~h}$ instead of $2 \mathrm{~h}$ ) and catalyst loading (1-2 mol\% instead of $0.5 \mathrm{~mol} \%$ ) to access similarly sized all-cis polymers, poly5-8 (Fig. 3b) (see Supplementary Information). The ability to use different capping groups with similarly high cis selectivity should broaden the scope of monomers for the stereoretentive ADMET. Importantly, several synthesized polymers are structurally analogous to industrially-relevant polymers such as poly(ethylene terephthalate) (PET) for poly-1 and poly-5.

The lower cis-selectivity observed at $50{ }^{\circ} \mathrm{C}$ with $\mathbf{R u - 3}$ prompted an investigation of temperature modulation as a means to dictate the content of cis and trans olefins in polyalkenamers. Decreasing amounts of cis olefins (from $\sim 70 \%$ to $\sim 30 \%$ ) were obtained when the ADMET polymerization was performed at $50{ }^{\circ} \mathrm{C}$ or $80{ }^{\circ} \mathrm{C}$ for increased reaction times (6-16 h) (Fig. 4a and Supplementary Tables 1-8). Olefin isomerization has been reported in ADMET processes with Ru metathesis catalysts containing an NHC ligand such as Ru-2. Several mechanisms have been postulated for this isomerization, including a $\mathrm{Ru}-\mathrm{H}$ species and metal allyl complexes derived from decomposed catalyst ${ }^{35-37}$. Notably, these pathways generally lead to concomitant alkene migration, which was indeed observed using Ru-2 (Supplementary Fig. 5). However, hydrolysis of poly-1 revealed that olefin migration does not take place with stereoretentive Ru-3, neither at room temperature, nor at higher temperatures (Fig. 4b). Hydrolytic degradation of cis-rich poly-1, poly-2, poly-3, poly-5, poly-6, and poly-7 under basic conditions cleanly delivered the cis isomer of oct-4-ene-1,8-diol (15) or dec-5-ene-1,10-diol (S8). While the exact mechanism of isomerization remains unclear, modulation of the cis/trans content without olefin migration was successfully performed with all monomers thereby
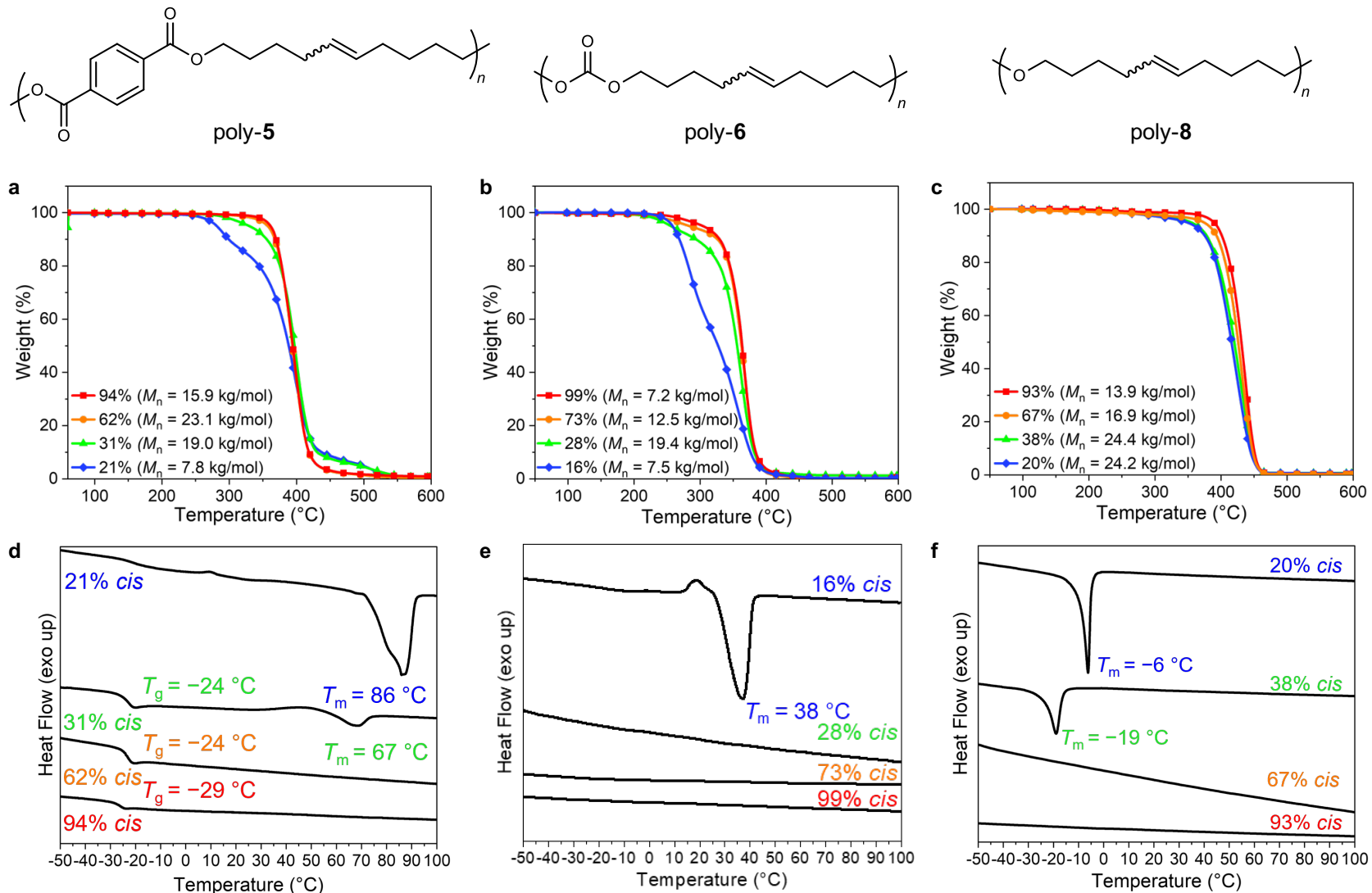

Fig. 5. Relationship between polymer stereochemistry and thermal properties. TGA thermograms of poly-5 (a), poly$6(\mathbf{b})$, and poly-8 (c). DSC thermograms of poly-5 (d), poly-6 (e), and poly-8 (f). 
providing access to a library of polyalkenamers with tailored backbone geometries from single building blocks. Importantly, the lack of olefin migration engenders more reproducible polymer properties ${ }^{38}$.

The thermal properties of the synthesized polyalkenamers with varying cis/trans ratios were analyzed via thermogravimetric analysis (TGA) and differential scanning calorimetry (DSC) (Fig. 5 for selected polymers and supporting information). While the range of molar masses $(\sim 7-25 \mathrm{~kg} / \mathrm{mol})$ resulting from the ADMET step-growth process renders the deconvolution of the impact of olefin stereochemistry challenging in some cases, comparison of polyalkenamers of similar sizes revealed enhanced stability with an increase in cis content (Fig. 5a-c). For poly-5 with $94 \%$ cis double bonds $\left(M_{\mathrm{n}}=15.9 \mathrm{~kg} / \mathrm{mol}\right)$, a decomposition temperature $\left(T_{\mathrm{d}}\right)$ recorded at $5 \%$ mass loss was observed at $365^{\circ} \mathrm{C}$ compared to $360{ }^{\circ} \mathrm{C}$ for $62 \%$ cis $\left(M_{\mathrm{n}}=23.1 \mathrm{~kg} / \mathrm{mol}\right)$ and $355^{\circ} \mathrm{C}$ for $31 \%$ cis $\left(M_{\mathrm{n}}=19.0 \mathrm{~kg} / \mathrm{mol}\right)$ (Fig. 5a). The $T_{\mathrm{d}}$ of poly-6 decreased by $46{ }^{\circ} \mathrm{C}$ when going from $99 \%$ cis to $16 \%$ cis for almost identical molar masses (Fig. 5b). Poly-8 exhibited a $T_{\mathrm{d}}$ of $390{ }^{\circ} \mathrm{C}$ for the $93 \%$ cis polymer $\left(M_{\mathrm{n}}=13.9 \mathrm{~kg} / \mathrm{mol}\right)$ as opposed to $374{ }^{\circ} \mathrm{C}$ for a $67 \%$ cis polymer $\left(M_{\mathrm{n}}=16.9 \mathrm{~kg} / \mathrm{mol}\right.$, Fig. $\left.5 \mathrm{c}\right)$. Analogously, all other synthesized polyalkenamers had thermal stabilities that varied with cis content (Supplementary Tables 9-16). DSC revealed a clear influence of cis-alkene content on thermal transitions as depicted in the thermograms in Fig. 5d-f, which is in line with reports by Buchard ${ }^{39}$ and Dove and Becker ${ }^{3,40}$. In addition to small variations of glass transition temperatures $\left(T_{\mathrm{g}}\right)$, striking differences in crystalline behavior were observed. For example, cis-rich poly-5, poly-6, and poly-8 appeared amorphous via DSC, while the same polyalkenamers with a majority of trans olefins exhibited both a melting $\left(T_{\mathrm{m}}\right)$ and a crystallization temperature $\left(T_{\mathrm{c}}\right)$. Poly-5 with only $31 \%$ and $22 \%$ cis olefins displayed a $T_{\mathrm{m}}$ at 67 and $86{ }^{\circ} \mathrm{C}$, respectively (Fig. 5d). The only sample of poly-6 to present a $T_{\mathrm{m}}\left(38^{\circ} \mathrm{C}\right)$ contained only $16 \% \mathrm{cis}$ linkages (Fig. 5e). Meanwhile, all other samples of poly-6 had no observable thermal transitions. Poly-8 showcased the most diverse thermal profile as a function of alkene stereochemistry. No thermal transitions could be detected with the $93 \%$ and $67 \%$ cis forms, but $T_{\mathrm{m}}$ 's and $T_{\mathrm{c}}$ 's were measured for samples with decreased cis content (38\% and 20\%) (Fig. 5f). DSC analysis of the two trans-rich poly-8 revealed sharp $T_{\mathrm{m}}$ 's at $-6{ }^{\circ} \mathrm{C}(20 \%$ cis $)$ and $-19{ }^{\circ} \mathrm{C}(38 \%$ cis $)$. Other synthesized polyalkenamers such as poly-7 displayed amorphous characteristics regardless of cis content with no thermal transitions detected in the DSC (Supplementary Fig. 22). While the nature of the polar groups and the number of methylenes in the repeating unit clearly impacts the phase transitions of the polyalkenamers, controlling the geometry of alkenes throughout the backbone provides an additional handle to tune the thermal properties of a variety of polymers.

Unprecedented control over the molecular structure and physical properties of polyalkenamers —including polyesters, polycarbonates, polysulfites, and polyethers - has been achieved through stereocontrolled ADMET. This method capitalizes on methyl- or ethyl-capped diene monomers to impart both the stereochemical information and catalyst stability critical to the polymerization process. Over $99 \%$ cis-selectivity was achieved for a variety of polymers including unsaturated polyesters, polycarbonates, polysulfites, and polyethers, which is a testament to the versatility of this method. The high reactivity of stereoselective dithiolate Ru catalysts towards cis monomers led to low catalyst loading $(0.5 \mathrm{~mol} \%)$, rapid reaction at room temperature $(2-4 \mathrm{~h})$, and tolerance toward trans monomer impurities, which are all attractive features for large-scale implementation. Stereoretention during the polymerization process was found to be sensitive to the reaction conditions, which provided a functional handle to modulate the ratio of cis:trans alkene units within the polymer backbone. This unique stereocontrol was harnessed to produce a variety of polyalkenamers with predictable cis:trans ratios from 20:80 to $>99: 1$ and to study the influence of alkene geometry over the thermal properties of the macromolecules. Increased thermal stability was generally correlated to increased cis olefin content and thermal transitions such as $T_{\mathrm{g}}, T_{\mathrm{m}}$, and $T_{\mathrm{c}}$ were greatly affected by the stereochemistry of the alkenes in the backbone. Of note, structural analogs of PET, a high commodity polyester, were prepared and exhibited tunable phase transition temperatures and efficient depolymerization via hydrolysis. This process provides a practical and efficient handle to control material properties for a large variety of olefin-containing polymers, which aligns well with the polymer field's pursuit of precise macromolecular structures for soft materials with designable properties and functionality ${ }^{41}$.

\section{References}

1) Roman, D.; Sauer, M.; Beemelmanns, C., Applications of the Horner-Wadsworth-Emmons Olefination in Modern Natural Product Synthesis. Synthesis 2021, 53, 2713-2739. 
2) Worch, J. C.; Prydderch, H.; Jimaja, S.; Bexis, P.; Becker, M. L.; Dove, A. P., Stereochemical enhancement of polymer properties. Nat. Rev. Chem. 2019, 3, 514-535.

3) Bell, C. A.; Yu, J.; Barker, I. A.; Truong, V. X.; Cao, Z.; Dobrinyin, A. V.; Becker, M. L.; Dove, A. P., Independent Control of Elastomer Properties through Stereocontrolled Synthesis. Angew. Chem. Int. Ed. 2016, 55, 13076-13080.

4) Ricci, G.; Pampaloni, G.; Sommazzi, A.; Masi, F., Dienes Polymerization: Where We Are and What Lies Ahead. Macromolecules 2021, 54, 5879-5914.

5) Yang, X.; Gitter, S. R.; Roessler, A. G.; Zimmerman, P. M.; Boydston, A. J., An Ion-Pairing Approach to Stereoselective Metal-Free Ring-Opening Metathesis Polymerization. Angew. Chem. Int. Ed. 2021, 60, 13952-13958.

6) Liu, J.; Lam, J. W. Y.; Jim, C. K. W.; Ng, J. C. Y.; Shi, J.; Su, H.; Yeung, K. F.; Hong, Y.; Faisal, M.; Yu, Y.; Wong, K. S.; Tang, B. Z., Thiol-Yne Click Polymerization: Regio- and Stereoselective Synthesis of Sulfur-Rich Acetylenic Polymers with Controllable Chain Conformations and Tunable Optical Properties. Macromolecules 2011, 44, 68-79.

7) Kent, E. G.; Swinney, F. B., Properties and Applications of trans-1,4-Polyisoprene. Ind. Eng. Chem. Prod. Res. Dev. 1966, 5, 134-138.

8) Bhowmick, A. K.; Kuo, C. C.; Manzur, A.; Arthur, A. M.; Intyre, D. M., Properties of cis-and transpolyisoprene blends. J. Macromol. Sci., Part B: Phys. 1986, 25, 283-306.

9) Baboo, M.; Dixit, M.; Sharma, K.; Saxena, N. S., Mechanical and thermal characterization of cispolyisoprene and trans-polyisoprene blends. Polym. Bull. 2011, 66, 661-672.

10) Montgomery, T. P.; Ahmed, T. S.; Grubbs, R. H., Stereoretentive Olefin Metathesis: An Avenue to Kinetic Selectivity. Angew. Chem. Int. Ed. 2017, 56, 11024-11036.

11) Keitz, B. K.; Fedorov, A.; Grubbs, R. H., Cis-Selective Ring-Opening Metathesis Polymerization with Ruthenium Catalysts. J. Am. Chem. Soc. 2012, 134, 2040-2043.

12) Khan, R. K. M.; Torker, S.; Hoveyda, A. H., Readily Accessible and Easily Modifiable Ru-Based Catalysts for Efficient and Z-Selective Ring-Opening Metathesis Polymerization and Ring-Opening/CrossMetathesis. J. Am. Chem. Soc. 2013, 135, 10258-10261.

13) Schrock, R. R., Synthesis of Stereoregular Polymers through Ring-Opening Metathesis Polymerization. Acc. Chem. Res. 2014, 47, 2457-2466.

14) Koh, M. J.; Khan, R. K. M.; Torker, S.; Yu, M.; Mikus, M. S.; Hoveyda, A. H., High-value alcohols and higher-oxidation-state compounds by catalytic Z-selective cross-metathesis. Nature 2015, 517, 181-186.

15) Song, J.-A.; Peterson, G. I.; Bang, K.-T.; Ahmed, T. S.; Sung, J.-C.; Grubbs, R. H.; Choi, T.-L., RuCatalyzed, cis-Selective Living Ring-Opening Metathesis Polymerization of Various Monomers, Including a Dendronized Macromonomer, and Implications to Enhanced Shear Stability. J. Am. Chem. Soc. 2020, $142,10438-10445$.

16) Michaudel, Q.; Kempel, S.J.; Hsu, T.-W.; deGruyter, J.N., E vs. Z Selectivity in Olefin Metathesis Through Catalyst Design. In Comprehensive Organometallic Chemistry IV. Elsevir, 2022. in press doi: 10.1016/B978-0-12-820206-7.00114-1.

17) Müller, D. S.; Baslé, O.; Mauduit, M., A tutorial review of stereoretentive olefin metathesis based on ruthenium dithiolate catalysts. Beilstein J. Org. Chem. 2018, 14, 2999-3010.

18) Grandner, J. M.; Shao, H.; Grubbs, R. H.; Liu, P.; Houk, K. N., Origins of the Stereoretentive Mechanism of Olefin Metathesis with Ru-Dithiolate Catalysts. J. Org. Chem. 2017, 82, 10595-10600.

19) Johns, A. M.; Ahmed, T. S.; Jackson, B. W.; Grubbs, R. H.; Pederson, R. L., High Trans Kinetic Selectivity in Ruthenium-Based Olefin Cross-Metathesis through Stereoretention. Org. Lett. 2016, 18, 772775.

20) Hsu, T.-W.; Kim, C.; Michaudel, Q., Stereoretentive Ring-Opening Metathesis Polymerization to Access All-cis Poly(p-phenylenevinylene)s with Living Characteristics. J. Am. Chem. Soc. 2020, 142, $11983-$ 11987.

21) Hsu, T.-W.; Kempel, S. J.; Michaudel, Q., All-cis poly(p-phenylene vinylene)s with high molar masses and fast photoisomerization rates obtained through stereoretentive ring-opening metathesis polymerization of [2,2]paracyclophane dienes with various aryl substituents. J. Polym. Sci. 2022, 60, 569-578. 
22) Caire da Silva, L.; Rojas, G.; Schulz, M. D.; Wagener, K. B., Acyclic diene metathesis polymerization: History, methods and applications. Prog. Polym. Sci. 2017, 69, 79-107.

23) Pribyl, J.; Wagener, K. B.; Rojas, G., ADMET polymers: synthesis, structure elucidation, and function. Mater. Chem. Front. 2021, 5, 14-43.

24) Wagener, K. B.; Boncella, J. M.; Nel, J. G., Acyclic diene metathesis (ADMET) polymerization. Macromolecules 1991, 24, 2649-2657.

25) Rojas, G.; Inci, B.; Wei, Y.; Wagener, K. B., Precision Polyethylene: Changes in Morphology as a Function of Alkyl Branch Size. J. Am. Chem. Soc. 2009, 131, 17376-17386.

26) Aitken, B. S.; Lee, M.; Hunley, M. T.; Gibson, H. W.; Wagener, K. B., Synthesis of Precision Ionic Polyolefins Derived from Ionic Liquids. Macromolecules 2010, 43, 1699-1701.

27) Weychardt, H.; Plenio, H., Acyclic Diene Metathesis Polymerization of Divinylarenes and Divinylferrocenes with Grubbs-Type Olefin Metathesis Catalysts. Organometallics 2008, 27, 1479-1485.

28) Xu, C.; Shen, X.; Hoveyda, A. H., In Situ Methylene Capping: A General Strategy for Efficient Stereoretentive Catalytic Olefin Metathesis. The Concept, Methodological Implications, and Applications to Synthesis of Biologically Active Compounds. J. Am. Chem. Soc. 2017, 139, 10919-10928.

29) Guoshun, Y.; Keda, H.; Yang, Q., Cis/Cis-2,5-dipropenylthiophene monomers for high-molecular-weight poly(2,5-thienylene vinylene)s through acyclic diene metathesis polymerization. J. Polym. Sci., Part A: Polym. Chem. 2014, 52, 591-595.

30) cis-hex-4-en-1-ol ( $>95 \%$ purity) costs $\$ 8.17 / \mathrm{g}$ (TCI, 2022) and cis-oct-5-en-1-ol ( $\geq 97 \%$ purity) costs $\$ 0.84 / \mathrm{g}$ (Sigma Aldrich, 2022).

31) Patton, J. T.; Boncella, J. M.; Wagener, K. B., Acyclic diene metathesis (ADMET) polymerization: the synthesis of unsaturated polyesters. Macromolecules 1992, 25, 3862-3867.

32) Wagener, K. B.; Patton, J. T., Acyclic diene metathesis (ADMET) polymerization. Synthesis of unsaturated polycarbonates. Macromolecules 1993, 26, 249-253.

33) Wagener, K. B.; Brzezinska, K., Acyclic diene metathesis (ADMET) polymerization: synthesis of unsaturated polyethers. Macromolecules 1991, 24, 5273-5277.

34) Gaines, T. W.; Nakano, T.; Chujo, Y.; Trigg, E. B.; Winey, K. I.; Wagener, K. B., Precise Sulfite Functionalization of Polyolefins via ADMET Polymerization. ACS Macro Lett. 2015, 4, 624-627.

35) Fokou, P. A.; Meier, M. A. R., Studying and Suppressing Olefin Isomerization Side Reactions During ADMET Polymerizations. Macromol. Rapid Commun. 2010, 31, 368-373.

36) Engel, J.; Smit, W.; Foscato, M.; Occhipinti, G.; Törnroos, K. W.; Jensen, V. R., Loss and Reformation of Ruthenium Alkylidene: Connecting Olefin Metathesis, Catalyst Deactivation, Regeneration, and Isomerization. J. Am. Chem. Soc. 2017, 139, 16609-16619.

37) Courchay, F. C.; Sworen, J. C.; Ghiviriga, I.; Abboud, K. A.; Wagener, K. B., Understanding Structural Isomerization during Ruthenium-Catalyzed Olefin Metathesis: A Deuterium Labeling Study. Organometallics 2006, 25, 6074-6086.

38) Qin, H.; Chakulski, B. J.; Rousseau, I. A.; Chen, J.; Xie, X.-Q.; Mather, P. T.; Constable, G. S.; Coughlin, E. B., Synthesis and Characterization of Unsaturated Thermotropic Polyesters Prepared via Acyclic Diene Metathesis Polymerization. Macromolecules 2004, 37, 5239-5249.

39) McGuire, T. M.; Pérale, C.; Castaing, R.; Kociok-Köhn, G.; Buchard, A., Divergent Catalytic Strategies for the Cis/Trans Stereoselective Ring-Opening Polymerization of a Dual Cyclic Carbonate/Olefin Monomer. J. Am. Chem. Soc. 2019, 141, 13301-13305.

40) Stubbs, C. J.; Worch, J. C.; Prydderch, H.; Becker, M. L.; Dove, A. P., Unsaturated Poly(ester-urethanes) with Stereochemically Dependent Thermomechanical Properties. Macromolecules 2020, 53, 174-181.

41) Lodge, T.P., Celebrating 50 Years of Macromolecules. Macromolecules 2017, 50, 9525-9527.

\section{Acknowledgments}

This work was supported by Texas A\&M University. The NMR facility in the department of Chemistry (TAMU) and the Soft Matter Facility (TAMU) were utilized. The authors thank Umicore for the generous donation of metathesis catalysts, Dr. Adam Johns for helpful discussions, Dr. Julia Pribyl for insightful discussions on ADMET 
polymerization, and Dr. Peiran Wei for his help with TGA/DSC analysis. The authors acknowledge the financial support of the Petroleum Research Fund managed by the American Chemical Society under Grant Number 60540DNI7 and the Welch Foundation under Grant Number (A-2004-20190330).

\section{Author contributions}

T.-W.H., S.J.K., and A.P.F.T. performed research. All authors designed research and analyzed data. Q.M., S.J.K, and T.-W.H. wrote the paper and Supplementary Information. T.-W.H. and S.J.K. contributed equally to this work.

\section{Competing interests}

Authors declare that they have no competing interests. 